\title{
Time-Varying Behavior of Stock Prices, Volatility Dynamics and Beta Risk in Industry Sector Indices of the Shanghai Stock Exchange
}

\author{
Dimitrios Koutmos \\ Leeds University Business School \\ University of Leeds \\ Leeds, LS2 9JT, United Kingdom \\ Tel: 44-791-542-0227Ｅ-mail: D.Koutmos@Leeds.ac.uk
}

Received: September 12, 2012

doi:10.5430/afr.v1n2p109
Accepted: October 9, 2012

Published: October 10, 2012

URL: http://dx.doi.org/10.5430/afr.v1n2p109

\begin{abstract}
This paper examines time-varying stock price and volatility dynamics of constituent industry sector indices in the Shanghai Stock Exchange. It finds that market beta risk is priced in the time-series movements of stock prices and responds positively to rises in non-diversifiable risk. The asset pricing implication here is that investors demand a higher required rate of return during rises in aggregate stock market volatility. Finally, this paper identifies which industries exhibit the highest degree of volatility persistence and how this impacts their respective beta estimates. It shows time-dependence in beta risk for all the sector indices and, finally, in contrast to studies which examine developed markets, there is no statistical evidence of volatility asymmetry in these industries. This suggests that 'good' and 'bad' news exert an equal impact on the conditional variance process on Chinese stock prices.
\end{abstract}

Keywords: Shanghai Stock Exchange, Time-varying beta risk, China

\section{Introduction}

The mounting evidence over the past few decades supports the notion of nonlinear dynamics in movements of asset returns. Despite being conventional wisdom in present-day empirical asset pricing, this observation continues to intrigue us and is a source of inspiration for much of the advancement in asset pricing and econometrics (e.g. Bollerslev et al. 1992; Engle 2001; Merton 1973). From a risk management perspective, it is fundamental to understand what the driving forces behind such nonlinear movements are in order to identify and hedge against sources of risk as well as estimate future expected returns of assets given their risk characteristics.

Current events seem to corroborate the view that stock prices behave in a nonlinear fashion. Shiller (2000) argues that the excess volatility in stock prices we are experiencing is wrought by irrational behavior and not shifts in demand commensurate to rational expectations. Thus, as a result of the formation and bursting of such market bubbles, it is no surprise we see that stock returns exhibit negative skewness and can take very large negative values with higher probabilistic likelihood than is otherwise suggested by a normal distribution. The finance profession has taken divergent paths in trying to rationalize this. Classical asset pricing argues that, in the presence of bad news, investors' required rate of return rises and they sell their positions and wait until expected returns rise to the appropriate level commensurate to this risk. Selling their positions puts downward pressure on stock prices and can produce such negative skewness observed in stock returns. Campbell and Hentschel (1992) dub this the 'volatility feedback effect' and it is widely cited as a plausible explanation to the negative relation between volatility and historical realized stock returns that is so commonly reported (e.g. Lundblad 2007).

Meanwhile, behavioral finance has entertained the possibility that investor heterogeneity and irrationality is a major driving force of stock prices (e.g., De Long et al. 1990; Shleifer and Vishny 1997; Shiller 2000). Such findings support the view that there are heterogeneous traders who do not make investment decisions solely on the basis of the conditional first and second moments of assets' return distributions. Most recently, Koutmos (2012) examines a cross-section of developed markets and reports that there is an interaction between different groups of investors and that such interaction may impact their respective demand functions for risky assets.

The aforementioned has contributed to our understanding of what drives stock prices and, from a risk management perspective, carries implications in terms of the methods used to model volatility. Traditionally, volatility in asset 
prices is perceived to reflect sources of risk and has been estimated using a simple unconditional variance computation based on historical price data. This approach is essential in classical asset pricing theory such as the capital asset pricing model (CAPM) of Sharpe (1964) and Lintner (1965) in order to compute unconditional betas for stocks and portfolios of assets. Graham and Harvey (2001) find, based on their survey evidence, that a large proportion of CFO's still use the CAPM for cost of capital estimation.

Estimating risk however on the basis of historical prices implicitly assumes risk and investors' degree of risk aversion is time-invariant or 'static' in nature. Such an assumption is dubious and may inaccurately represent ex ante risks. French et al. (1987), Glosten et al. (1993), Merton (1973), Nelson (1991) and Schwert and Seguin (1990), among many other authors, argue that risk and investment opportunities are time-varying and linked to shifts in the business cycle.

Given that academic studies support the notion of time-varying volatility, the next logical question to ask is: What is the relevance of this to industry portfolios and how are such portfolios impacted by aggregate stock market volatility? This study seeks to address this question in the context of China's relatively unexplored stock market and to see whether commonly observed phenomena typically discernable in stock markets such as the U.S. and other European markets is also evident in Chinese stock prices.

The remainder of this paper is organized as follows. Section 2 describes the motivation for this paper and outlines the empirically testable propositions that will be considered. Section 3 presents that data that is used and some preliminary findings. Section 4 presents the econometric methodology that is used along with major findings and, finally, section 5 concludes the paper.

\section{Motivation and Empirically Testable Propositions}

The development and subsequent application of the aforementioned theories and econometric methodologies has predominantly been based on U.S. and European stock markets with relatively little attention being given to China's rapidly growing stock market. This presents an opportunity to research this important market given that it is perhaps the fastest growing economy in the world and is piquing the interest of international institutional investors who are eager to invest in this market. The investment program initiated by the Chinese government in 2002 referred to as "qualified foreign institutional investor" (QFII) was meant to make its stock market more accessible to credible foreign investment entities which, since the inception of this program, consist of many large investment banks and funds as well as well-respected national universities. Since the creation of this program, interest in China's stock market has grown.

It is of interest therefore to understand more about the time-varying behavior of Chinese stock market prices and to understand how various industry sectors respond to shifts in aggregate stock market volatility. Academic literature has only recently began to study China's stock market with a view of reconciling established asset pricing theories with its dynamic economic market forces. Much of this research focuses on the pricing mechanisms of local A- and foreign B-shares; Fung et al. (2000) examine the pricing of local A- and foreign B-shares and test whether markets for these two classes of shares are segmented. Chan et al. (2008) look at the impact of information asymmetry on the equity prices of these two classes and how this impacts investors.

Other authors examine whether stock prices in China are consistent with the efficient market hypothesis and the view that they reflect all available information. Conclusions from these studies tend to be mixed and inconclusive (e.g., Charles and Darné 2009; Groenewold et al. 2003; Lee et al. 2001; Lima and Tabak 2004; Seddighi and Nian 2004). Kang et al. (2002) argue that there has been a lack of rigorous empirical research into stock price behavior in China and it appears prices may be driven by investor sentiment. Sun and Tong (2003) investigate the impact of privatization on firms' performance given that there has been steady liberalization of Chinese publicly-listed firms.

The aforementioned sheds new light into China's dynamic stock market and economy. However, it is still yet to be rigorously explored how China's stock prices behave and if such behavior 'fits' into conventional asset pricing paradigms that have become so widely accepted in the profession. Eun and Huang (2007) find that market beta risk is not priced in the cross-sectional variation of expected stock returns in China. Similarly, Wu (2011) finds that market beta has no explanatory power and there is limited evidence supporting the 'value effect' as being a significant factor in explaining variations in expected returns in the context of the Fama-French (1993; 1995) three-factor asset pricing model.

In light of this, the objective here is to estimate time-varying beta risk in the Chinese stock market to understand how stock prices evolve through time. By looking at the cross-section of industry sectors in the Shanghai Stock Exchange, this paper shows which industries are most and least sensitive to shocks in aggregate stock market volatility and how 
industries' beta risk responds to such shocks. In particular, this paper addresses (i) whether the conditional variance of the respective industry sectors' stock returns is time-dependent and heteroskedastic; (ii) to what extent does volatility respond to positive and negative news and whether volatility asymmetry is statistically identifiable; (iii) the behavior of beta risk for each of the industry sectors in the presence of rising aggregate stock market volatility.

\section{Nature of data and preliminary findings}

To provide some insights into the aforementioned, this paper collects data on the industry sector indices which comprise the Shanghai Stock Exchange. The data is collected from the Shanghai Stock Exchange's website (www.sse.com.cn) and consists of a total of ten industries that are important to China's livelihood: Energy, materials, industrials, consumer discretionary, consumer staples, healthcare, financials, information technology, telecommunications, and utilities, respectively. Stock prices are daily and are denominated in Renminbi. Unconditional returns, $r_{i}$, are computed in continuously compounded terms as $r_{i}=100 * \ln \left(P_{i, t} / P_{i, t-1}\right)$. The sample for all sectors including the Shanghai Stock Exchange 180 (SSE 180) market index ranges from January 9, 2009 to June 15, 2012 for a total of 830 observations.

Table 1 identifies each of the industry sector indices, their identifier code that can be used to download historical prices, and a brief description of the number of constituent companies in each respective sector and the nature of that industry's operations. According to the Shanghai Stock Exchange's website, which lists each of the constituent companies for each industry sector, these companies are selected because they are the largest and most well-established companies within their respective industry. As such, fluctuations in the stock prices of these sectors provide useful economic information and reflect shifts in the market conditions of their respective industries. A time series plot of each of the index sectors is illustrated in Figure 1.

The proxy for the market portfolio used in this paper is the SSE 180 which consists of some of the largest and most established companies in all of China. Altogether, these companies represent the various industries in China's economy and can serve as a broad benchmark for its aggregate stock market. Figure 2 displays a set of scatter plots, each of them plotting the industry sector index's return series on the vertical axis and returns on the SSE 180 on the horizontal axis along with a regression fit line. As is expected, there is a positive slope in the regression fit line since higher returns in the SSE 180 generally correspond with higher returns in each of the industry sectors and vice versa. It can also be visually seen from the scatter plots that there are observations in the symmetric quadrants $(+,+)$ and $(-,-)$ which indicate that the return series of the industry sectors and the SSE 180 can simultaneously take large positive and negative values

Table 2 presents some summary statistics and distributional properties for the returns of each industry sector index along with the SSE 180 market portfolio. The SSE 180 has a mean return of $0.0302 \%$, which corresponds to approximately $7.6 \%$ per annum. The highest mean returns were computed for the healthcare and consumer staples industries while industrials, utilities and telecommunications had the lowest mean returns which even lagged far behind the SSE 180 market index. Skewness and kurtosis measures indicate that the return series are generally negatively skewed and leptokurtic. This is a common empirical observation when working with financial time-series data (e.g., Fama 1965; Mandelbrot 1963). Such skewness may result from the bursting of stochastic bubbles that create sizeable negative returns or asymmetries in news disclosure to the public (e.g., Ekholm and Pasternack 2005; Blanchard and Watson 1982). The Anderson-Darling test statistic confirms that the respective return series depart from the general characteristics of a normal distribution.

The correlation between each sectors' returns with the returns on the market portfolio, $\rho_{i, M}$, are also reported in the last column of Table 2. The healthcare sector, which has the highest historical mean return, also has the lowest correlation with the market (0.3300), while the materials, industrials, energy and utilities sectors had the highest correlations with the market; $0.4939,0.4808,0.4690$ and 0.4690 , respectively.

\section{Econometric Framework}

\subsection{Volatility Estimation and Dynamics}

Extant literature identifies that linear dependencies exist in stock market returns and that the conditional mean distribution of returns can be a function of past residuals or past returns (e.g., Lo and MacKinlay 1988; Scholes and Williams 1977). Following Lo and MacKinlay (1988), the conditional mean for each sector's returns is specified using an autoregressive process of the order $k=1$, i.e., $\operatorname{AR}(1)$ :

$$
R_{t}=\alpha+\Omega_{1} R_{t-1}+\varepsilon_{t}
$$


The term $\Omega_{1} R_{t-1}$ serves to pick up any autocorrelation as a result of momentum or non-synchronous trading and, thus, $\varepsilon_{t}$ is a pure white noise process.

The conditional variance of the error term is modeled via the asymmetric EGARCH(1,1) of Nelson (1991) and specified as follows:

$$
\log \left(\sigma_{t}^{2}\right)=\alpha_{0}+\alpha_{1}\left|z_{t-1}\right|+\alpha_{2} z_{t-1}+\beta \log \left(\sigma_{t-1}^{2}\right) .
$$

The conditional variance, $\sigma_{t}^{2}$, is specified as a nonlinear function of past residuals and its own past value and where, $z_{t}=\varepsilon_{t} / \sigma_{t}$ is the standardized residual. The EGARCH specification is log-linear in nature and whereby the term $\alpha_{2} z_{t-1}$ captures the asymmetric impact of bad news in the sense that if $\alpha_{2}$ is negative and statistically significant, it means that negative shocks (i.e. market declines) lead to more volatility than positive shocks (i.e. market upswings) of equal magnitude. The converse would be true if $\alpha_{2}$ is positive and statistically significant, implying that positive shocks to the market would lead to more volatility than negative shocks of equal magnitude. Finally, a statistically negligible value for $\alpha_{2}$ implies that both negative and positive shocks exert the same impact on the conditional variance process. The EGARCH specification is an advantageous specification to use because estimates for $\sigma_{t}^{2}$ are always positive and therefore it is not necessary to impose non-negativity constraints as may be necessary when working with other conventional GARCH models.

Studies examining the behavior of stock returns tend to use the normal density function. Such an approach however may yield parameter estimates that are asymptotically inefficient since standardized residuals obtained from GARCH-type models appear leptokurtic relative to the normal distribution (e.g., Bollerslev 1987). To cope with this, authors can use a density function with thicker tails such as the Generalized Error Distribution (GED). Such an approach is advantageous since parameter estimates are not as influenced excessively by statistically improbable events such as market crashes and therefore standard error estimates may be more reliable. This paper uses the GED distribution and its density function is expressed as follows:

$$
f\left(\mu_{t}, \sigma_{t}, v\right)=[v / 2][\Gamma(3 / v)]^{1 / 2}[\Gamma(1 / v)]^{-3 / 2}\left(1 / \sigma_{t}\right) \exp \left\{-[\Gamma(3 / v) / \Gamma(1 / v)]^{v 2}\left(\varepsilon_{t} / \sigma_{t}\right)^{v}\right\}
$$

where $\Gamma($.$) is the gamma function and the scale parameter is v$, which are degrees of freedom that can be endogenously estimated. The GED yields a normal distribution for $v=2$ and a Laplace, or double exponential distribution, for $v=1$.

The parameter vector is estimated given the initial values for $\varepsilon_{t}$ and $\sigma_{t}$ by maximizing the log-likelihood function over the sampling period, expressed as follows:

$$
L(\Theta \mid k, p, q)=\sum_{t=1}^{T} \log f\left(\mu_{t}, \sigma_{t}^{2}, v\right),
$$

where the parameter vector, conditional mean, conditional variance, and scale parameter, or, degrees of freedom, are indicated by $\Theta, \mu_{t}, \sigma_{t}^{2}$, and $v$, respectively. Given that the log-likelihood function is nonlinear, the method of maximization used in this paper is based on the algorithm proposed by Berndt et al. (1974).

Volatility estimates for the $\operatorname{AR}(1)-E G A R C H(1,1)$ model from the returns of each sector index, as well as the SSE 180, are reported in Table 3 . The EGARCH in this paper is estimated using a $(1,1)$ specification since similar studies find that lower order GARCH models are sufficient in capturing the 'stylized facts' of stock returns such as heteroskedasticity and volatility clustering (e.g., Bollerslev et al. 1992). Findings indicate that the conditional variance for all the sectors is a function of past innovations and past values of the conditional variance, as is indicated by the significance of $\alpha_{1}$ and $\beta$, respectively. Remarkably, the parameter $\alpha_{2}$ is statistically insignificant for all sectors which indicates that positive and negative shocks in the market exert a similar impact on the conditional variance process. This is in sharp contrast to studies which implement asymmetric GARCH-type models and generally find that international markets exhibit asymmetry in their volatility process (e.g., Koutmos 2012).

Figure 3 shows plots of the returns and conditional variance estimates for each sector index. It can visually be seen that sector index returns reveal common 'stylized facts' such as heteroskedasticity and volatility clustering. During periods of intense volatility clustering, it is no surprise that the conditional variance estimate is relatively higher in that period.

Table 3 also reports estimates for the half-life (HL) of a shock, which is an intuitive measure of the degree of volatility persistence associated with the autoregressive coefficient $\beta$ from the EGARCH specification in (2):

$$
\beta^{\mathrm{HL}}=1 / 2 \text {, or, } \mathrm{HL}=\log _{e}(1 / 2) / \log _{e}(\beta) \text {. }
$$


Of all the sectors, the healthcare and consumer staples industries have the lowest half-lives ( 7.32 and 7.76 days, respectively). This low persistence may be attributable to the fact that these are relatively 'safe' industries given that there is an inelastic demand for their goods and services regardless of aggregate market conditions and fluctuations. On the other hand, the autoregressive parameter $\beta$ is near unity for the financial sector, suggesting a very high degree of persistence. The HL estimates confirm this; a shock to its volatility process lasts indefinitely. This can also be observed visually by looking at its conditional variance plot in Figure 3 which shows an extremely high level of persistence from one day to the next.

Residual based diagnostics from the AR(1)-EGARCH $(1,1)$ are reported in Table 4 . These tests check whether the standardized residuals (i.e. $\varepsilon_{t} / \sigma_{t}$ ) from the model, firstly, have zero mean and unit variance and, secondly, whether they are linearly and nonlinearly independent. As is reported, the means and variances of the standardized residuals fulfill this requirement. Independence is checked using the Ljung-Box (LB) statistic which shows that the standardized residuals are uncorrelated up to ten lags. These statistics provide support for the model and suggest it is a good fit for the data.

\subsection{Heteroskedastic Market Model with Time-Varying Betas}

In light of extant findings, the purpose of this paper is to explore the time-varying nature of stock price volatility of various industries in the Shanghai Stock Exchange and to examine how each respective industry responds to shocks in aggregate stock market volatility. To accomplish this, it adopts the Schwert and Seguin (1990) market model which allows us to quantify the degree of heteroskedasticity in stock returns and to assess its effects. Exploring a cross-section of industry sectors using such an approach will give us a better idea of how the betas of these industries respond to aggregate stock market volatility. As already mentioned, beta estimates derived from a 'static' CAPM may only provide an ex post view of risk.

Schwert and Seguin (1990) begin by defining a single index model for stock return heteroskedasticity:

$$
\operatorname{cov}_{t-1}\left(R_{i, t}, R_{j, t}\right)=\alpha_{0, i, j}+\alpha_{1, i, j} \sigma_{t-1}^{2}\left(R_{m, t}\right) .
$$

If $\alpha_{1, i, j}=0$, volatility in the aggregate market returns, $R_{m, t}$, results in no changes to portfolio variances and covariances. In the situation where $\alpha_{0, i, j}=0$ and $\alpha_{1, i, j} \neq 0$, the portfolio's volatility is related proportionally to aggregate stock market volatility. Finally, if $\alpha_{0, i, j}$ and $\alpha_{1, i, j}$ are nonzero, the portfolio's returns are heteroskedastic and not proportional to aggregate stock market volatility. Glejser (1969) argues of a scenario where the variance of residuals is nonproportional to the regressor and dubs this as 'mixed heteroskedasticity.'

The return generating process is defined as

$$
R_{i, t}=\alpha_{i}+\beta_{i} R_{m, t}+\varepsilon_{i, t}, \varepsilon_{i, t} \sim\left(0, \sigma_{i}^{2}\right)
$$

where $R_{i, t}$ and $R_{m, t}$ are the returns on the sector index and market portfolio, respectively. The coefficient $\beta_{i}$ reflects relative nondiversifiable risk of sector index $i$ and is defined as $\beta_{i}=\operatorname{cov}\left(R_{i, t}, R_{m, t}\right) / \sigma_{m, t}^{2}$. This beta coefficient is a linear function of the covariance matrix of sector index returns to returns on the market portfolio which, in this case, is the SSE 180 market index:

$$
\beta_{i}=\sum_{i=1}^{N} w_{j} \sigma_{i, j} / \sum_{i=1}^{N} \sum_{j=1}^{N} w_{i} w_{j} \sigma_{i, j}
$$

where $w_{j}$ represents weights for the aggregate stock market for the $j$ th sector index and, since there are 10 sector indices considered here, $N=10$.

Based on the single index model in (6), the beta coefficient for sector $i$ in time period $t$ is

$$
\beta_{i, t}=\frac{\sum_{j=1}^{N} w_{j}\left(a_{0, i, j}+a_{1, i, j} \sigma_{m, t}^{2}\right)}{\sum_{i=1}^{N} \sum_{j=1}^{N} w_{i} w_{j}\left(a_{0, i, j}+a_{1, i, j} \sigma_{m, t}^{2}\right)},
$$

which reduces to

$$
\beta_{i, t}=\frac{\bar{a}_{0, i}}{\sigma_{m, t}^{2}}+\overline{\mathrm{a}}_{1, i}
$$

Equation (10) holds using the constraint that the weighted average beta coefficient equals 1.0 and, therefore, for each time period $t, \sum w_{i} \bar{a}_{0, i}=0$ and $\sum w_{i} \bar{a}_{1, i}=1$. The denominator in (10) thus is equivalent to $\sigma_{m, t}^{2}$ by default. The notation, $\overline{\mathrm{a}}_{m, i}$ reflects $\sum w_{i} a_{m, i, j}$ for $m=0,1$. If $\bar{a}_{0, i}$ is nonzero, then the beta for sector index $i$ will fluctuate with the level of aggregate volatility of the SSE 180 market index. Such a scenario can be incorporated into the market model in (7) by inserting the term $\left(R_{m, t} / \hat{\sigma}_{m, t}^{2}\right)$, which Schwert and Seguin (1990) dub as the heteroskedastic market model: 


$$
R_{i, t}=\alpha_{i}+\beta_{i} R_{m, t}+\delta_{i}\left(R_{m, t} / \hat{\sigma}_{m, t}^{2}\right)+\varepsilon_{i, t}, \quad t=1, \ldots, T,
$$

whereby $\beta_{i, t}=\beta_{i}+\left(\delta_{i} / \sigma_{m, t}^{2}\right)$, and $\delta_{i}$ measures $\bar{a}_{0, i}$.

Table 5 shows ordinary least squares (OLS) estimates of the heteroskedastic market model (11), along with the estimates of the Glejser regression:

$$
(\pi / 2)^{1 / 2}\left|\hat{\varepsilon}_{i, t}\right|=z_{0, i}+z_{l, i} \hat{\sigma}_{m, t}+\mathrm{v}_{i, t}
$$

Table 5 also contains weighted least squares (WLS) estimates of (11), where the predicted residual standard deviations of the Glejser regression in (12) are used to form the weights.

From these estimates, we can examine the impact of volatility in the SSE 180 market index and its impact on the various sectors. The direction and magnitude of the coefficient $\delta_{i}$ in equation (11) will tell us about this impact; namely, if $\delta_{i}>0$, then as volatility on the SSE 180 market index, $\hat{\sigma}_{m, t}^{2}$, rises the time-varying beta is expected to fall. In other words, the systematic risk in sector index $i$ moves opposite to variations in market volatility. Conversely, if $\delta_{i}<0$, then, as market volatility, $\hat{\sigma}_{m, t}^{2}$, rises, we would expect time-varying beta to rise accordingly. This implies that systematic risk on sector index $i$ and market volatility vary positively with one another.

From the OLS estimates in Table 5, we can see that for all industry sector indices $\delta_{i}$ is negative and statistically significant. This implies that their respective betas respond positively to systematic risk in the SSE 180 market index and, as market volatility rises, we expect to see investors demand a higher required rate of return in order to be compensated for this nondiversifiable risk. These findings are somewhat in contrast to those of Eun and Huang (2007) and $\mathrm{Wu}$ (2011) who document that market beta risk has what appears a limited role in explaining variations in stock returns. In this paper, we see that there is a role for beta risk and perhaps the reason for the mixed results is that inferences are being made from a 'static' single-period capital asset pricing model. Time-varying betas computed here show that beta responds positively to nondiversifiable risk and, consistent with classical asset pricing, risk averse investors are expected to demand a higher required rate of return when such risk rises. In terms of the coefficient $\beta_{i}$, we see that it is positive and statistically significant implying that returns on all sectors vary, to some extent, in tandem with the aggregate market. WLS estimates also reflect qualitatively consistent conclusions with the OLS parameter estimates.

Finally, Table 6 presents the average of the time-varying betas computed over the sampling period for each of the sector indices using the OLS and WLS regression estimates, respectively. The estimated coefficients provide valuable economic information to market participants and academic researchers in terms of the risk characteristics of the various industries. We can see that the healthcare, telecommunications and consumer staples sectors, in that order, have the lowest average betas for the sampling period. As mentioned, this stems from the relatively inelastic demand there is for goods and services from those industries regardless of whether there is an up or down market. Conversely, the materials, financials and energy sectors, in that order, have the highest average betas. This is consistent with the view that these are procyclical industries which have potential of doing better when the overall economy is doing well but are likely to perform poorly during recessionary periods.

\section{Conclusions}

This paper examines the time-varying beta risk of industry sector indices in the Shanghai Stock Exchange with the intent to provide new evidence on the behavior of stock prices in China's relatively unexplored stock market. It looks specifically at ten industry sectors in order to estimate their beta risk and to see how they respond to shifts in aggregate stock market volatility. The findings are consistent with the classical asset pricing paradigm that investors demand higher returns in the presence of higher market risk. More specifically, this paper shows, using the heteroskedastic market model proposed by Schwert and Seguin (1990), that industries' betas respond positively to rises in such nondiversifiable risk. finding is in contrast with other studies that have relied on 'static' beta estimates derived from single-period capital asset pricing models and which find that beta has little role in explaining variations in expected returns in the Chinese stock market.

Using the EGARCH methodology of Nelson (1991), this paper also reports on the volatility persistence of the various industry sectors and identifies which industries have high and low persistence. It is remarkable to see that, unlike volatility dynamics of European or American stock markets, there is no statistically reliable evidence of volatility asymmetry. In other words, 'good' and 'bad' news exert an equal impact on the conditional volatility process. This is perhaps a characteristic that is unique to Chinese stocks and merits more attention in the future.

By exploring a cross-section of industry sectors, this paper presents to academics and market participants the stock price behavior in China's market and identifies which industries are most and least sensitive to market shocks. It also 
thus makes meaningful inferences as to which industries are procyclical and countercyclical, information that can help in making more informed investment decisions in the presence of up and down markets. More empirical research will undoubtedly focus on China's rich and unique stock markets in the years to come in an attempt to see how established asset pricing theories and econometric models relate to this economy and what the major driving forces are behind its stock price dynamics.

\section{References}

Berndt, E.K., Hall, H.B., Hall, R.E., \& Hausman, J.A. (1974). Estimation and inference in nonlinear structural models. Annals of Economic and Social Measurement, 4, 653-666.

Blanchard, O. \& Watson, M.W. (1982). Bubbles, rational expectations and financial markets. National Bureau of Economic Research, working paper No. 945.

Bollerslev, T. (1987). A conditionally heteroskedastic time series model for speculative prices and rates of return. Review of Economics and Statistics, 69, 542-547. http://dx.doi.org/10.2307/1925546

Bollerslev, T., Chou, R.Y. \& Kroner, K.F. (1992). ARCH modeling in finance: a review of the theory and empirical evidence. Journal of Econometrics, 52, 5-59. http://dx.doi.org/10.1016/0304-4076(92)90064-X

Campbell, J. \& Hentschel, L. (1992). No news is good news: an asymmetric model of changing volatility in stock returns. Journal of Financial Economics, 31, 281-318. http://dx.doi.org/10.1016/0304-405X(92)90037-X

Chan, K., Menkveld, A. \& Yang, Z.S. (2008). Information asymmetry and asset prices: evidence from the China foreign share discount. Journal of Finance, 63, 159-196. http://dx.doi.org/10.1111/j.1540-6261.2008.01313.x.

Charles, A. \& Darné, O. (2009). The random walk hypothesis for Chinese stock markets: evidence from variance ratio tests. Economic Systems, 33, 117-126. http://dx.doi.org/10.1016/j.ecosys.2008.09.003.

De Long, B.J., Shleifer, A., Summers, L.H. \& Waldmann, R.J. (1990). Positive feedback investment strategies and destabilizing rational speculation. Journal of Finance, 45, 379-395. http://dx.doi.org/10.1111/j.1540-6261.1990.tb03695.x

Ekholm, A. \& Pasternack, D. (2005). The negative news threshold - an explanation for negative skewness in stock returns. European Journal of Finance, 11, 511-529. http://dx.doi.org/10.1080/1351847042000286702.

Engle, R. (2001). GARCH 101: The use of ARCH/GARCH models in applied econometrics. Journal of Economic Perspectives, 15, 157-168. http://dx.doi.org/10.2307/2696523.

Eun, C.S. \& Huang, W. (2007). Asset pricing in China's domestic stock markets: is there any logic? Pacific-Basin Finance Journal, 15, 452-480. http://dx.doi.org/10.1016/j.pacfin.2006.11.002.

Fama, E. (1965). The behavior of stock market prices. Journal of Business, 38, 34-105. http://dx.doi.org/10.1086/294743

Fama, E. \& French, K.R. (1993). Common risk factors in the returns on stocks and bonds. Journal of Financial Economics, 33, 3-56. http://dx.doi.org/10.1016/0304-405X(93)900.

Fama, E. \& French, K.R. (1995). Size and book-to-market factors in earnings and returns. Journal of Finance, 50, 131-155. http://dx.doi.org/10.1111/j.1540-6261.1995.tb05169.x

French, K.R., Schwert, G.W. \& Stambaugh, R. (1987). Expected stock returns and volatility. Journal of Financial Economics, 19, 3-29. http://dx.doi.org/10.1016/0304-405X(87)90026-2.

Fung, H.G., Lee, W. \& Leung, W.K. (2000). Segmentation of the A and B Chinese equity markets. Journal of Financial Research, 23, 179-195.

Glejser, H. (1969). A new test for heteroskedasticity. Journal of the American Statistical Association, 64, 316-323. http://dx.doi.org/10.1080/01621459.1969.10500976

Glosten, L.R., Jagannathan, R. \& Runkle, D.E. (1993). On the relation between the expected value and the volatility of the nominal excess return on stocks. Journal of Finance, 48, 1779-1801. http://dx.doi.org/10.1111/j.1540-6261.1993.tb05128.x

Graham, J.R. \& Harvey, C.R. (2001). The theory and practice of corporate finance: evidence from the field. Journal of Financial Economics, 60, 187-243. http://dx.doi.org/10.1016/S0304-405X(01)00044-7.

Groenewold, N., Tang, S.H.K. \& Wu, Y. (2003). The efficiency of the Chinese stock market and the role of banks. Journal of Asian Economics, 14, 593-609. http://dx.doi.org/10.1016/S1049-0078(03)00097-6. 
Kang, J., Liu, M.-H. \& Ni, S.X. (2002). Contrarian and momentum strategies in the China stock market: 1993-2000. Pacific Basin Finance Journal, 10, 243-265. http://dx.doi.org/10.1016/S0927-538X(02)00046-X.

Koutmos, D. (2012). An intertemporal capital asset pricing model with heterogeneous expectations. Journal of International Financial Markets, Institutions \& Money, 22, 1176-87. http://dx.doi.org/10.1016/j.intfin.2012.05.007.

Lee, C.F., Chen, G.-M. \& Rui, O.M. (2001). Stock returns and volatility on China's stock markets. Journal of Financial Research, 24, 523-543.

Lima, E.J.A. \& Tabak, B.M. (2004). Tests of the random walk hypothesis for equity markets: evidence from China, Hong Kong, Singapore. Applied Economics Letters, 11, 255-258. http://dx.doi.org/10.1080/13504850410001674911

Lintner, J. (1965). The valuation of risky assets and the selection of risky investments in stock portfolios and capital budgets. Review of Economics and Statistics, 47, 13-37. http://dx.doi.org/10.2307/1924119

Lo, A.W. \& MacKinley, A.C. (1988). Stock market prices do not follow random walks: evidence from a simple specification test. Review of Financial Studies, 1, 41-66. http://dx.doi.org/10.1093/rfs/1.1.41.

Lundblad, C. (2007). The risk-return tradeoff in the long-run. Journal of Financial Economics, 85, 123-150. http://dx.doi.org/10.1016/j.jfineco.2006.06.003.

Mandelbrot, B. (1963). The variation of certain speculative prices. Journal of Business, 36, 394-419. http://dx.doi.org/10.1086/294632.

Merton, R.C. (1973). An intertemporal capital asset pricing model. Econometrica, 41, 867-888. http://dx.doi.org/10.2307/1913811

Nelson, D.B. (1991). Conditional heteroskedasticity in asset returns: a new approach. Econometrica, 59, 347-370. http://dx.doi.org/10.2307/2938260

Newey, W. \& West, K. (1987). A simple positive-definite heteroskedasticity and autocorrelation consistent covariance matrix. Econometrica, 55, 703-708. http://dx.doi.org/10.2307/1913610

Scholes, M. \& Williams, J. (1977). Estimating betas from non-synchronous data. Journal of Financial Economics, 5, 309-327. http://dx.doi.org/10.1016/0304-405X(77)90041-1.

Schwert, G.W. \& Seguin, P.J. (1990). Heteroskedasticity in stock returns. Journal of Finance, 45, 1129-1155. http://dx.doi.org/10.1111/j.1540-6261.1990.tb02430.x.

Seddighi, H.R. \& Nian, W. (2004). The Chinese stock exchange market: operations and efficiency. Applied Financial Economics, 14, 785-797. http://dx.doi.org/10.1080/0960310042000180826.

Sharpe, W. (1964). Capital asset prices: a theory of market equilibrium under conditions of risk. Journal of Finance, 19, 425-442. http://dx.doi.org/10.1111/j.1540-6261.1995.tb05169.x.

Shiller, R.J. (2000). Irrational Exuberance. Princeton University Press, Princeton, New Jersey.

Sun, Q. \& Tong, W.H.S. (2003). China share issue privatization: the extent of its success. Journal of Financial Economics, 70, 183-222. http://dx.doi.org/10.1016/S0304-405X(03)00145-4.

$\mathrm{Wu}, \mathrm{H}$. (2011). The value and size effect - are there firm-specific risks in China's domestic stock markets? International Journal of Economics and Finance, 3, 26-37. 
Table 1. Description of Sector Indices in the Shanghai Stock Exchange

\begin{tabular}{|c|c|c|}
\hline Sector index & Identifier Code & Brief description \\
\hline Energy & 000032.SS & $\begin{array}{l}\text { This sector consists of } 30 \text { constituent companies engaged in the } \\
\text { business of mining, processing, manufacturing and distributing } \\
\text { energy resources such as coal, oil, gas, and electricity, to name only } \\
\text { a few resources. }\end{array}$ \\
\hline Materials & 000033.SS & $\begin{array}{l}\text { This sector consists of } 50 \text { constituent companies engaged in the } \\
\text { business of manufacturing and distributing materials such as } \\
\text { aluminum, steel, nickel, titanium, gold, zinc, carbon, tungsten, that } \\
\text { can later be used by consumers or companies at various stages in } \\
\text { their production process. }\end{array}$ \\
\hline Industrials & 000034.SS & $\begin{array}{l}\text { This sector consists of } 50 \text { constituent companies engaged in the } \\
\text { business of industrial production, construction projects, and } \\
\text { distribution. Companies in this sector may receive raw materials to } \\
\text { initiate industrial construction projects such as, for example, } \\
\text { railways, airports and airliners, science, technology, and devices for } \\
\text { harnessing energy. }\end{array}$ \\
\hline Consumer discretionary & 000035.SS & $\begin{array}{l}\text { This sector consists of } 50 \text { constituent companies engaged in the } \\
\text { production and distribution of nonessential customer goods and } \\
\text { services. These may include retailers, consumer durables, media, } \\
\text { and automobile and component companies. }\end{array}$ \\
\hline Consumer staples & 000036.SS & $\begin{array}{l}\text { This sector consists of } 30 \text { constituent companies that produce and } \\
\text { distribute essential customer goods and services. These may include } \\
\text { food, beverage and pharmaceutical companies. }\end{array}$ \\
\hline Healthcare & 000037.SS & $\begin{array}{l}\text { This sector consists of } 30 \text { constituent companies that produce } \\
\text { healthcare goods and services such as medical products and } \\
\text { biotechnology, as well as hospitals and their management. }\end{array}$ \\
\hline Financials & 000038.SS & $\begin{array}{l}\text { This sector consists of } 30 \text { constituent companies that provide } \\
\text { financial services to individual and commercial customers. It } \\
\text { includes banks, investment and insurance companies, and real } \\
\text { estate investment companies. }\end{array}$ \\
\hline Information technology & 000039.SS & $\begin{array}{l}\text { This sector consists of } 30 \text { constituent companies that research, } \\
\text { develop and distribute technological goods and services. It may } \\
\text { include software, computer, electronics, such as semiconductors, } \\
\text { and aerospace technology companies. }\end{array}$ \\
\hline Telecommunications & 000040.SS & $\begin{array}{l}\text { This sector consists of } 9 \text { constituent companies that provide } \\
\text { telecommunication goods and services. It may include radio, } \\
\text { television, telephone and internet service companies. }\end{array}$ \\
\hline Utilities & 000041.SS & $\begin{array}{l}\text { This sector includes } 29 \text { constituent utilities companies that may } \\
\text { include gas, electric, and water companies. }\end{array}$ \\
\hline SSE 180 Market index & 000010.SS & $\begin{array}{l}\text { The Shanghai Stock Exchange } 180 \text { Market Index consists of } 180 \text { of } \\
\text { some of the largest and most established companies which most } \\
\text { accurately reflect the performance of their respective sectors. The } \\
\text { aggregate returns of these companies forms the SSE } 180 \text { Market } \\
\text { Index, which can serve as a broad benchmark for the performance } \\
\text { of China's stock market. }\end{array}$ \\
\hline
\end{tabular}

Notes: This table provides a brief description of each index sector along with its identifier code. 
Table 2. Daily Return Summary Statistics

\begin{tabular}{lcccccc}
\hline \hline Sector index & $\begin{array}{c}\text { Mean } \\
(\%)\end{array}$ & $\begin{array}{c}\text { Standard } \\
\text { deviation }\end{array}$ & Skewness & Kurtosis & Anderson-Darling & $\boldsymbol{i}, \boldsymbol{M}$ \\
\hline \hline Energy & 0.0416 & 2.1315 & -0.0632 & 4.4916 & $3.9537^{*}$ & 0.4690 \\
Materials & 0.0538 & 2.0859 & -0.3347 & 4.4946 & $3.0156^{*}$ & 0.4939 \\
Industrials & 0.0039 & 1.6796 & -0.4854 & 4.7139 & $4.0054^{*}$ & 0.4808 \\
Consumer discretionary & 0.0572 & 1.8012 & -0.4570 & 4.3392 & $3.4453^{*}$ & 0.4370 \\
Consumer staples & 0.0707 & 1.6871 & -0.5447 & 4.0302 & $4.3496^{*}$ & 0.3980 \\
Healthcare & 0.0723 & 1.7784 & -0.3083 & 4.1176 & $3.7200^{*}$ & 0.3031 \\
Financials & 0.0340 & 1.7579 & -0.0427 & 4.4900 & $4.6510^{*}$ & 0.4024 \\
Information technology & 0.0533 & 2.0794 & -0.4983 & 3.7473 & $3.9378^{*}$ & 0.3882 \\
Telecommunications & -0.0090 & 1.8948 & -0.3530 & 3.9519 & $3.5504^{*}$ & 0.3612 \\
Utilities & 0.0086 & 1.5730 & -0.6664 & 5.1609 & $6.8050^{*}$ & 0.4690 \\
SSE 180 Market index & 0.0302 & 1.6343 & -0.3567 & 4.6557 & $4.6505^{*}$ & 1.0000 \\
\hline \hline
\end{tabular}

Notes: This table presents summary statistics for each of the index sectors and includes the mean $(\mu)$, standard deviation $(\sigma)$, and measures of skewness and kurtosis. The Anderson-Darling (A-D) statistic tests for normality and is calculated as $\mathrm{AD}=\sum_{i=1}^{n} \frac{1-2 i}{n}\left\{\ln \left(F_{0}\left[Z_{(i)}\right]\right)+\ln \left(1-F_{0}\left[Z_{(n+1-i)}\right]\right)\right\}-n$, where $F_{0}$ is the empirical normal distribution with estimated parameters $(\mu, \sigma), n$ is the sample size, and $Z_{(i)}$ is the $i^{\text {th }}$ standardized sample value. Its $5 \%$ critical value is $0.752 /\left[1+0.75 / T+2.25 / T^{2}\right]$, where $T$ is the number of observations. $\left.{ }^{*}\right)$ denotes significance at the $5 \%$ level at least. The coefficient, $\rho_{i, M}$, denotes the correlation between the returns of each sector index with those of the SSE 180.

Table 3. Maximum Likelihood Estimates of the AR-EGARCH Model

\begin{tabular}{lcccccc}
\hline \hline Sector index & $\alpha_{0}$ & $\alpha_{1}$ & $\alpha_{2}$ & $\beta$ & $\log \mathbf{L}$ & HL \\
\hline \hline \multirow{2}{*}{ Energy } & -0.0403 & 0.0710 & 0.0001 & 0.9899 & -1754.46 & 68.28 \\
& $(-2.108)^{*}$ & $(2.544)^{*}$ & $(0.004)$ & $(117.040)^{*}$ & & \\
Materials & -0.0615 & 0.1252 & -0.0006 & 0.9736 & -1738.84 & 25.91 \\
& $(-2.530)^{*}$ & $(3.499)^{*}$ & $(-0.033)$ & $(60.883)^{*}$ & & \\
Industrials & -0.0474 & 0.1127 & -0.0161 & 0.9595 & -1565.62 & 16.77 \\
& $(-1.960)^{*}$ & $(2.709)^{*}$ & $(-0.801)$ & $(35.636)^{*}$ & & \\
Consumer discretionary & -0.0607 & 0.1678 & -0.0339 & 0.9373 & -1622.80 & 10.70 \\
Consumer staples & $(-1.921)$ & $(3.263)^{*}$ & $(-1.288)$ & $(28.977)^{*}$ & & \\
& -0.1206 & 0.2572 & -0.0112 & 0.9146 & -1563.31 & 7.76 \\
Healthcare & $(-2.949)^{*}$ & $(4.242)^{*}$ & $(-0.342)$ & $(27.647)^{*}$ & & \\
& -0.0356 & $(0.1741)$ & $(-0.0060)$ & 0.9097 & -1622.29 & 7.32 \\
Financials & $(-1.020)$ & $(4.173)^{*}$ & $(-0.236)$ & $(21.721)^{*}$ & & \\
\multirow{2}{*}{ Information technology } & 0.0031 & -0.0064 & -0.0148 & 0.9995 & -1580.52 & 1385.95 \\
\multirow{2}{*}{ Telecommunications } & $(0.295)$ & $(-0.446)$ & $(-1.582)$ & $(598.42)^{*}$ & & \\
& -0.0901 & 0.2092 & 0.0078 & 0.9461 & -1742.31 & 12.51 \\
Utilities & $(-2.264)^{*}$ & $(3.865)^{*}$ & $(0.298)$ & $(39.205)^{*}$ & & \\
& -0.0391 & 0.1279 & -0.0082 & 0.9511 & -1678.85 & 13.83 \\
SSE 180 Market index & $(-1.334)$ & $(2.791)^{*}$ & $(-0.345)$ & $(30.601)^{*}$ & & \\
& -0.0714 & 0.1191 & 0.0050 & 0.9760 & -1485.26 & 28.53 \\
\hline \hline
\end{tabular}

Notes: This table presents estimates for the respective EGARCH parameters for each industry as well as the $\log$-likelihood function $(\log L)$ and half-life $(H L)$ of a shock to the conditional variance process. $\left(^{*}\right)$ denotes significance at the $5 \%$ level at least. 
Table 4. Residual Based Diagnostics

\begin{tabular}{lcccc}
\hline \hline Sector index & $\boldsymbol{E}\left(\varepsilon_{t} / \sigma_{t}\right)$ & $\boldsymbol{E}\left[\left(\varepsilon_{t} / \sigma_{t}\right)^{2}\right]$ & $\boldsymbol{L B}(\mathbf{1 0})$ & $\boldsymbol{L B}^{2}(\mathbf{1 0})$ \\
\hline \hline Energy & 0.0152 & 1.0021 & 4.4205 & 9.4352 \\
Materials & -0.0090 & 1.0032 & 6.7794 & 10.0760 \\
Industrials & -0.0322 & 1.0078 & 10.0490 & 14.3650 \\
Consumer discretionary & -0.0204 & 1.0052 & 7.1609 & 9.9103 \\
Consumer staples & -0.0320 & 1.0005 & 9.7308 & 7.6431 \\
Healthcare & 0.0050 & 1.0006 & 22.3340 & 4.2071 \\
Financials & 0.0101 & 0.9901 & 2.6544 & 16.9310 \\
Information technology & -0.0201 & 1.0018 & 8.5491 & 8.7054 \\
Telecommunications & -0.0383 & 1.0015 & 4.5604 & 6.2141 \\
Utilities & -0.0397 & 1.0073 & 7.0577 & 17.6250 \\
SSE 180 Market index & -0.0164 & 0.9997 & 6.5850 & 12.9160 \\
\hline \hline
\end{tabular}

Notes: This table presents residual based diagnostics. $E\left(\varepsilon_{t} / \sigma_{t}\right)$ and $E\left[\left(\varepsilon_{t} / \sigma_{t}\right)^{2}\right]$ are the mean and variance of the standardized residuals, respectively. $L B(10)$ and $L B^{2}(10)$ are Ljung-Box statistics for $E\left(\varepsilon_{t} / \sigma_{t}\right)$ and $E\left[\left(\varepsilon_{t} / \sigma_{t}\right)^{2}\right]$, respectively. LB is distributed as $\chi^{2}$ where the degrees of freedom are equal to the number of lags. 
Table 5. Heteroskedastic Market Model with Time-Varying Betas for Sector Index Portfolios

\begin{tabular}{|c|c|c|c|c|c|c|c|}
\hline Sector index & $\alpha_{i}$ & $\overline{\beta_{i}}$ & $\overline{\delta_{i}}$ & $R^{2}$ & $S(\hat{\boldsymbol{\epsilon}})$ & $z_{0, i}$ & $z_{1, i}$ \\
\hline \multicolumn{8}{|c|}{ Ordinary Least Squares Estimates } \\
\hline Energy & $\begin{array}{l}-0.0101 \\
(-0.158)\end{array}$ & $\begin{array}{c}1.4094 \\
(12.134)^{*}\end{array}$ & $\begin{array}{c}-2.1352 \\
(-7.288)^{*}\end{array}$ & 0.2672 & 1.8256 & $\begin{array}{c}2.1553 \\
(14.722)^{*}\end{array}$ & $\begin{array}{c}-0.1655 \\
(-3.208)^{*}\end{array}$ \\
\hline Materials & $\begin{array}{l}-0.0044 \\
(-0.085)\end{array}$ & $\begin{array}{c}1.5108 \\
(12.181)^{*}\end{array}$ & $\begin{array}{c}-2.3567 \\
(-7.195)^{*}\end{array}$ & 0.3041 & 1.7406 & $\begin{array}{c}2.0171 \\
(14.631)^{*}\end{array}$ & $\begin{array}{c}-0.1371 \\
(-2.820)^{*}\end{array}$ \\
\hline Industrials & $\begin{array}{l}-0.0414 \\
(-1.030)\end{array}$ & $\begin{array}{c}1.2064 \\
(11.375)^{*}\end{array}$ & $\begin{array}{l}-1.9066 \\
(-6.685)^{*}\end{array}$ & 0.2917 & 1.4145 & $\begin{array}{c}1.7044 \\
(14.864)^{*}\end{array}$ & $\begin{array}{c}-0.1463 \\
(-3.618)^{*}\end{array}$ \\
\hline Consumer discretionary & $\begin{array}{l}0.0070 \\
(0.154)\end{array}$ & $\begin{array}{c}1.2673 \\
(11.514)^{*}\end{array}$ & $\begin{array}{c}-2.1032 \\
(-7.226)^{*}\end{array}$ & 0.2553 & 1.5545 & $\begin{array}{c}1.6385 \\
(13.351)^{*}\end{array}$ & $\begin{array}{l}-0.0581 \\
(-1.342)\end{array}$ \\
\hline Consumer staples & $\begin{array}{l}0.0264 \\
(0.551)\end{array}$ & $\begin{array}{c}1.1385 \\
(11.856)^{*}\end{array}$ & $\begin{array}{c}-1.9492 \\
(-7.562)^{*}\end{array}$ & 0.2207 & 1.4901 & $\begin{array}{c}1.5328 \\
(13.224)^{*}\end{array}$ & $\begin{array}{l}-0.0356 \\
(-0.871)\end{array}$ \\
\hline Healthcare & $\begin{array}{l}0.0341 \\
(0.602)\end{array}$ & $\begin{array}{c}0.9837 \\
(9.960)^{*}\end{array}$ & $\begin{array}{c}-1.7498 \\
(-5.858)^{*}\end{array}$ & 0.1375 & 1.6525 & $\begin{array}{c}1.4933 \\
(11.228)^{*}\end{array}$ & $\begin{array}{l}0.0239 \\
(0.511)\end{array}$ \\
\hline Financials & $\begin{array}{l}-0.0232 \\
(-0.492)\end{array}$ & $\begin{array}{c}1.4735 \\
(14.085)^{*}\end{array}$ & $\begin{array}{c}-2.7861 \\
(-10.264)^{*}\end{array}$ & 0.2802 & 1.4923 & $\begin{array}{c}1.7513 \\
(14.482)^{*}\end{array}$ & $\begin{array}{c}-0.1353 \\
(-3.174)^{*}\end{array}$ \\
\hline Information technology & $\begin{array}{l}0.0019 \\
(0.033)\end{array}$ & $\begin{array}{c}1.3076 \\
(9.946)^{*}\end{array}$ & $\begin{array}{c}-2.1780 \\
(-6.131)^{*}\end{array}$ & 0.2024 & 1.8577 & $\begin{array}{c}1.8730 \\
(12.654)^{*}\end{array}$ & $\begin{array}{l}-0.0415 \\
(-0.795)\end{array}$ \\
\hline Telecommunications & $\begin{array}{l}-0.0448 \\
(-0.806)\end{array}$ & $\begin{array}{c}0.9986 \\
(7.677)^{*}\end{array}$ & $\begin{array}{c}-1.5519 \\
(-4.709)^{*}\end{array}$ & 0.1621 & 1.7350 & $\begin{array}{c}1.7868 \\
(13.011)^{*}\end{array}$ & $\begin{array}{l}-0.0499 \\
(-1.032)\end{array}$ \\
\hline Utilities & $\begin{array}{l}-0.0381 \\
(-0.998)\end{array}$ & $\begin{array}{c}1.2097 \\
(11.097)^{*}\end{array}$ & $\begin{array}{c}-2.0298 \\
(-7.302)^{*}\end{array}$ & 0.2983 & 1.3183 & $\begin{array}{c}1.3396 \\
(12.729)^{*}\end{array}$ & $\begin{array}{l}-0.0341 \\
(-0.919)\end{array}$ \\
\hline \multicolumn{8}{|c|}{ Weighted Least Squares Estimates } \\
\hline Energy & $\begin{array}{l}-0.0164 \\
(-0.258)\end{array}$ & $\begin{array}{c}1.4644 \\
(13.869)^{*}\end{array}$ & $\begin{array}{c}-2.2615 \\
(-8.134)^{*}\end{array}$ & 0.3159 & 1.8258 & & \\
\hline Materials & $\begin{array}{l}-0.0098 \\
(-0.161)\end{array}$ & $\begin{array}{c}1.5515 \\
(15.142)^{*}\end{array}$ & $\begin{array}{c}-2.4508 \\
(-9.149)^{*}\end{array}$ & 0.3461 & 1.7408 & & \\
\hline Industrials & $\begin{array}{l}-0.0459 \\
(-0.934)\end{array}$ & $\begin{array}{c}1.2560 \\
(15.623)^{*}\end{array}$ & $\begin{array}{c}-2.0210 \\
(-9.468)^{*}\end{array}$ & 0.3538 & 1.4147 & & \\
\hline Consumer discretionary & $\begin{array}{l}0.0087 \\
(0.160)\end{array}$ & $\begin{array}{c}1.2839 \\
(13.400)^{*}\end{array}$ & $\begin{array}{c}-2.1418 \\
(-8.726)^{*}\end{array}$ & 0.2720 & 1.5545 & & \\
\hline Consumer staples & $\begin{array}{l}0.0252 \\
(0.485)\end{array}$ & $\begin{array}{c}1.1460 \\
(12.327)^{*}\end{array}$ & $\begin{array}{l}-1.9664 \\
(-8.307)^{*}\end{array}$ & 0.2300 & 1.4902 & & \\
\hline Healthcare & $\begin{array}{l}0.0342 \\
(0.593)\end{array}$ & $\begin{array}{c}0.9803 \\
(9.220)^{*}\end{array}$ & $\begin{array}{c}-1.7417 \\
(-6.530)^{*}\end{array}$ & 0.1339 & 1.6526 & & \\
\hline Financials & $\begin{array}{l}-0.0237 \\
(-0.457)\end{array}$ & $\begin{array}{c}1.5164 \\
(17.561)^{*}\end{array}$ & $\begin{array}{c}-2.8846 \\
(-12.683)^{*}\end{array}$ & 0.3383 & 1.4925 & & \\
\hline Information technology & $\begin{array}{l}0.0019 \\
(0.028)\end{array}$ & $\begin{array}{c}1.3168 \\
(11.349)^{*}\end{array}$ & $\begin{array}{c}-2.1993 \\
(-7.447)^{*}\end{array}$ & 0.2105 & 1.8576 & & \\
\hline Telecommunications & $\begin{array}{l}-0.0451 \\
(-0.744)\end{array}$ & $\begin{array}{c}1.0144 \\
(9.414)^{*}\end{array}$ & $\begin{array}{c}-1.5883 \\
(-5.775)^{*}\end{array}$ & 0.1716 & 1.7351 & & \\
\hline Utilities & $\begin{array}{l}-0.0396 \\
(-0.860)\end{array}$ & $\begin{array}{c}1.2221 \\
(14.892)^{*}\end{array}$ & $\begin{array}{c}-2.0579 \\
(-9.837)^{*}\end{array}$ & 0.3115 & 1.3184 & & \\
\hline
\end{tabular}

Notes: This table presents parameter estimates for (11) and, of particular importance, is the coefficient $\delta_{i}$ which reflects the time-varying component of sectors' relative nondiversifiable risk. The significance of this coefficient tells us whether such relative nondiversifiable risk moves with aggregate stock market volatility and its sign tells us the direction. For OLS, t-statistics in parentheses report heteroskedasticity consistent estimates for (11) using the Newey-West method (Newey and West 1987). $S(\hat{\epsilon})$ is the residual standard deviation and $z_{0 i}$ and $z_{1 i}$ are parameter estimates of the Glejser regression (12) which uses its predicted residual standard deviations to form the weights for the WLS estimates. $\left(^{*}\right)$ denotes significance at the $5 \%$ level at least. 
Table 6. Average Time-Varying Betas

\begin{tabular}{lcc}
\hline & \multicolumn{2}{c}{ Average time-varying beta estimates } \\
\cline { 2 - 3 } Sector index & oLS & wLS \\
\hline \hline Energy & 1.4003 & 1.4553 \\
Materials & 1.5017 & 1.5424 \\
Industrials & 1.1973 & 1.2469 \\
Consumer discretionary & 1.2582 & 1.2748 \\
Consumer staples & 1.1294 & 1.1369 \\
Healthcare & 0.9746 & 0.9712 \\
Financials & 1.4644 & 1.5073 \\
Information technology & 1.2985 & 1.3077 \\
Telecommunications & 0.9895 & 1.0053 \\
Utilities & 1.2006 & 1.2130 \\
\hline \hline
\end{tabular}

Notes: This table reports the average time-varying beta of each sector index derived from the OLS and WLS regressions, respectively, of the heteroskedastic market model in (11). The weights for the WLS regression are obtained from the predicted residual standard deviations of the Glejser regression in (12).

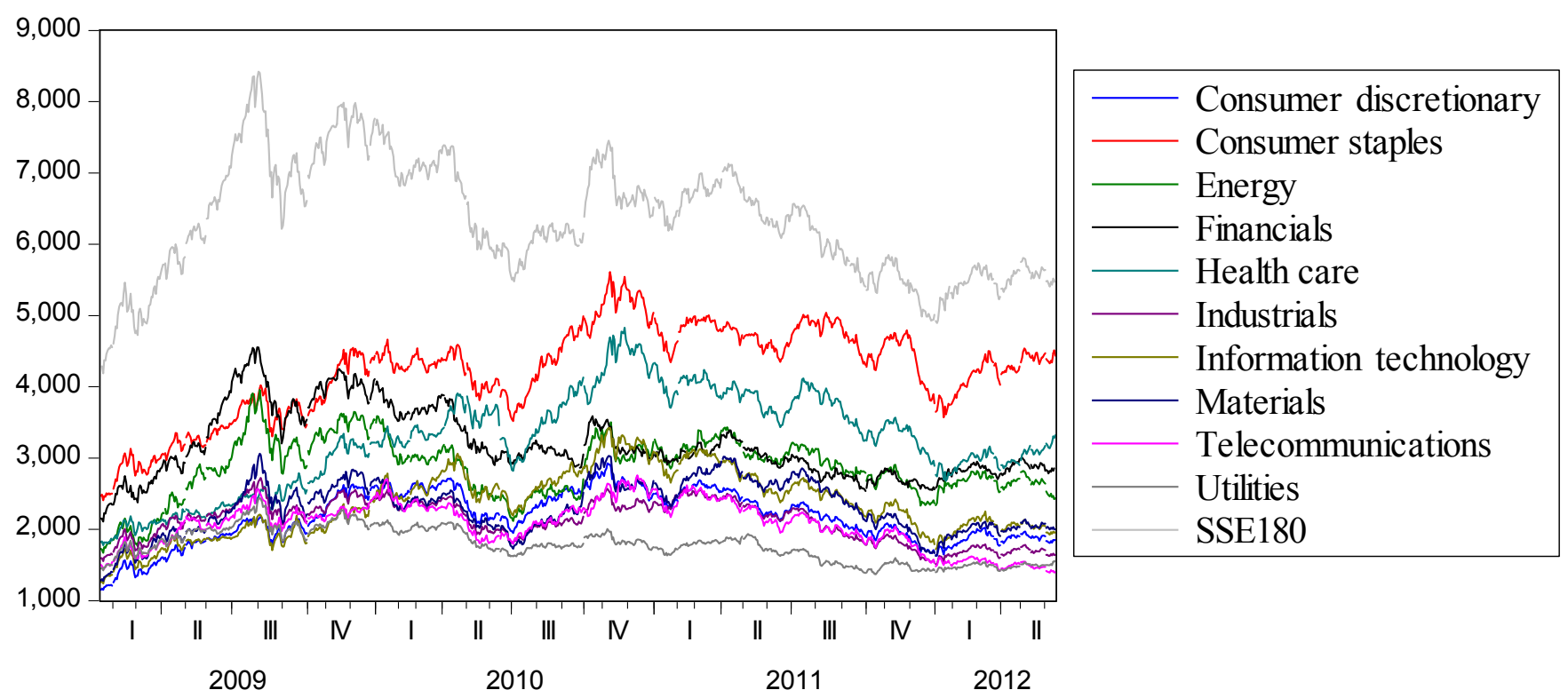

Figure 1. Time Series Plot of Index Stock Prices 

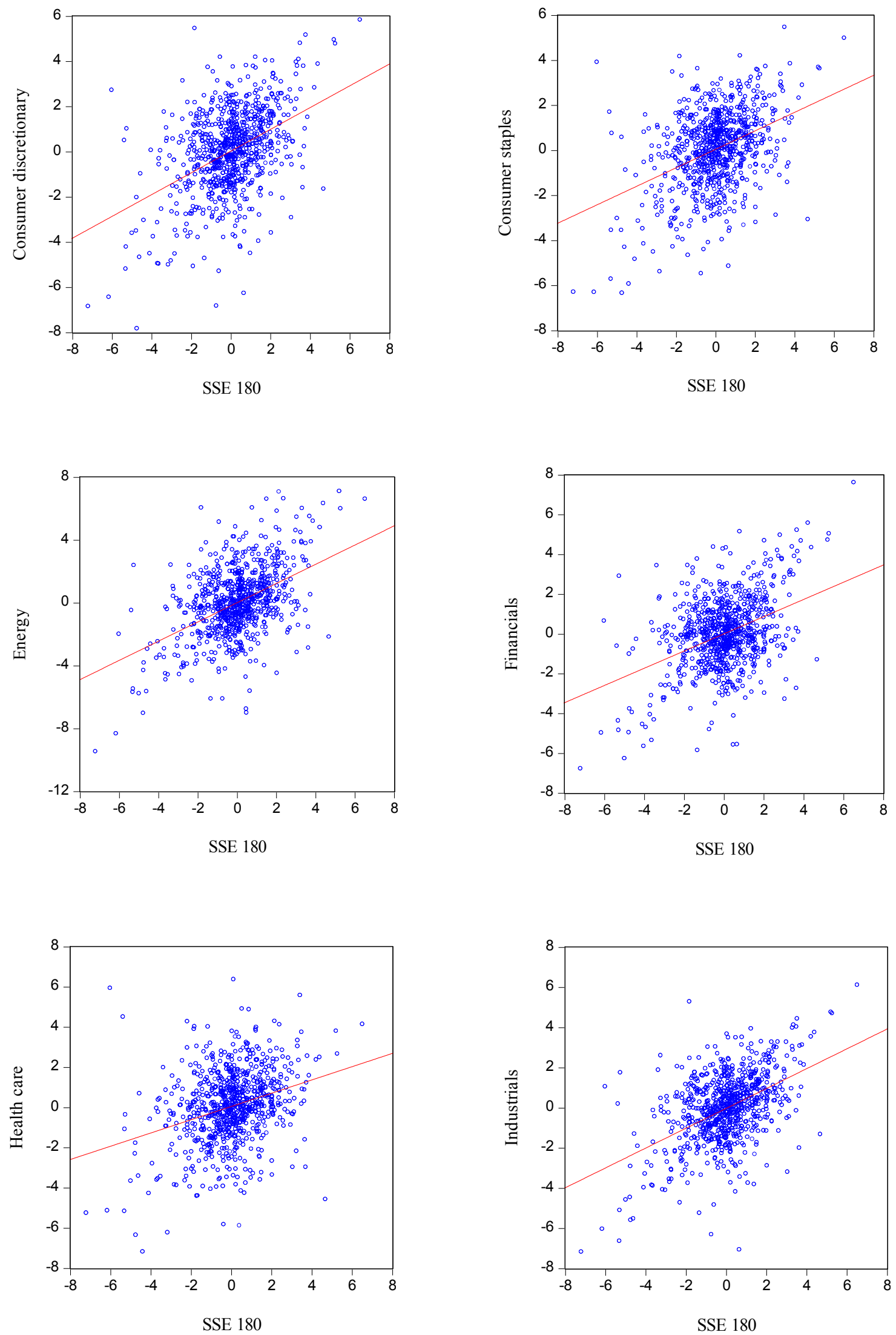

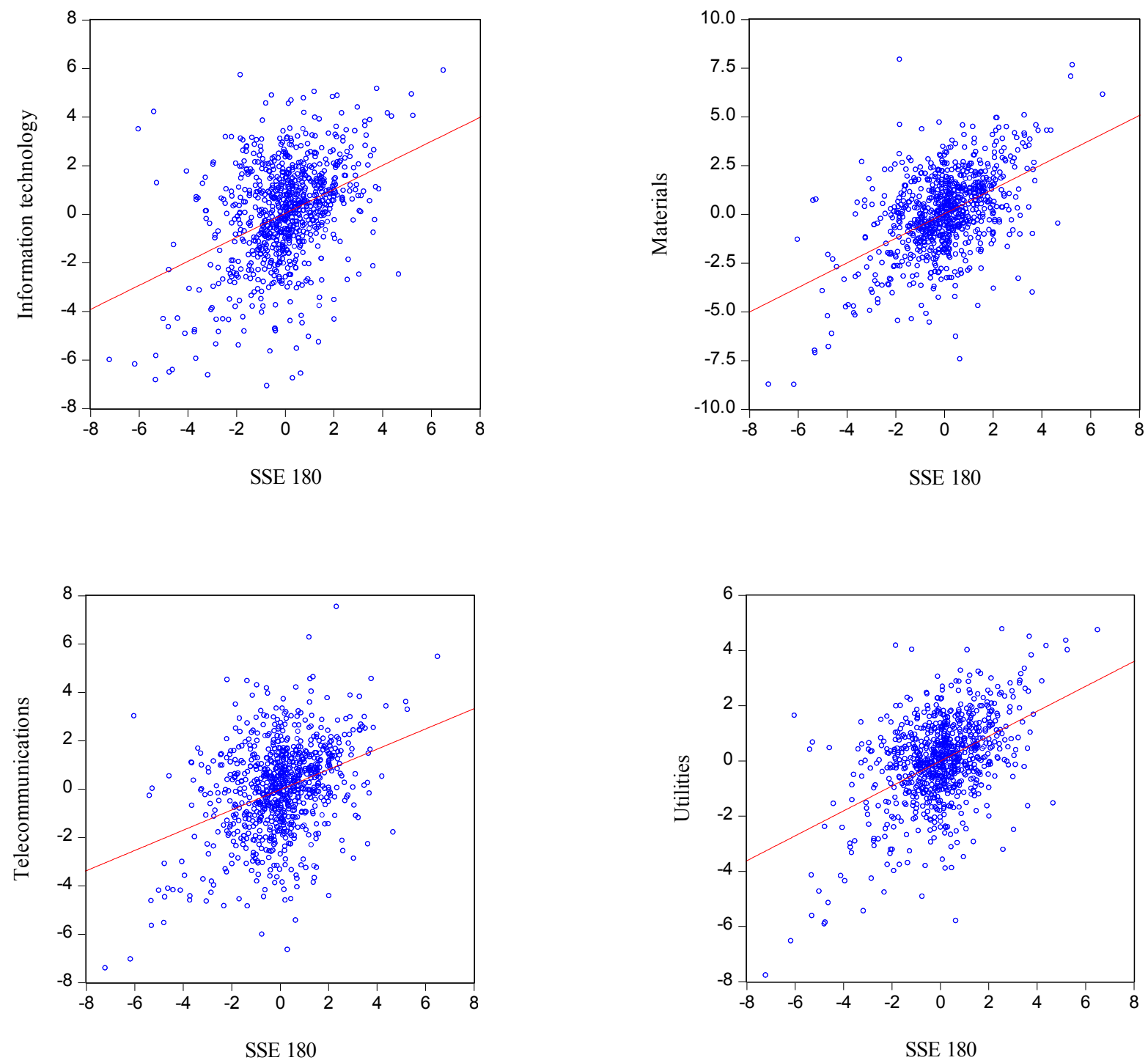

Figure 2. Plot of Index Returns against Market Returns 
Consumer discretionary

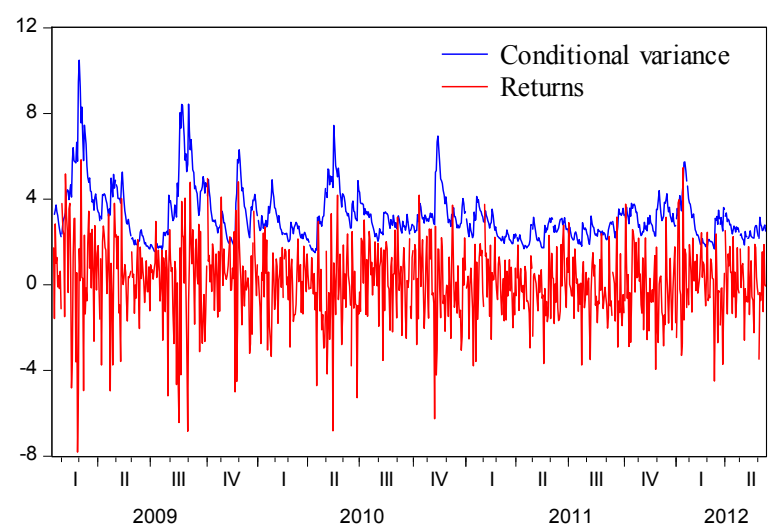

Energy

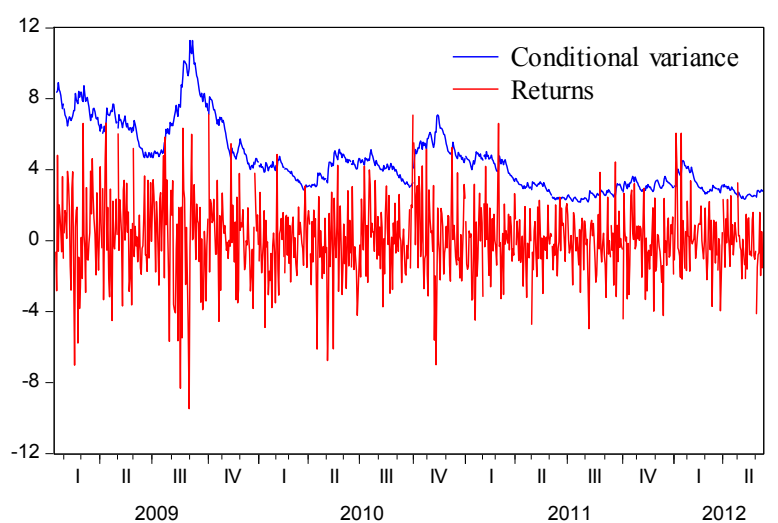

Health care

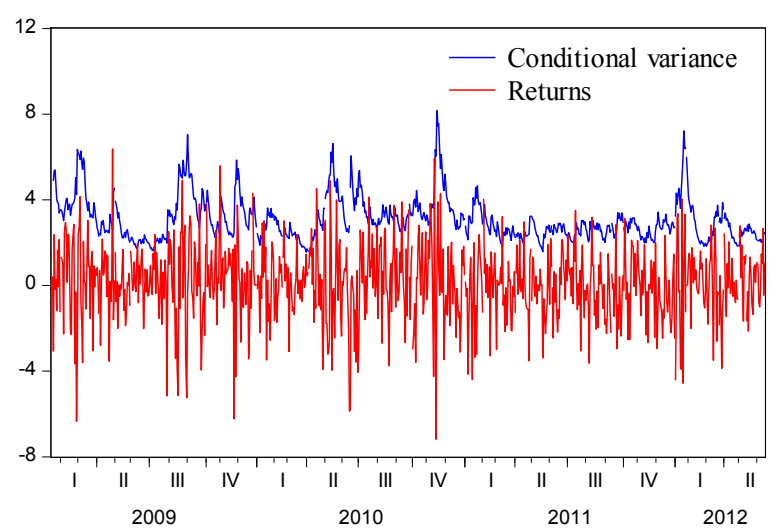

Consumer staples

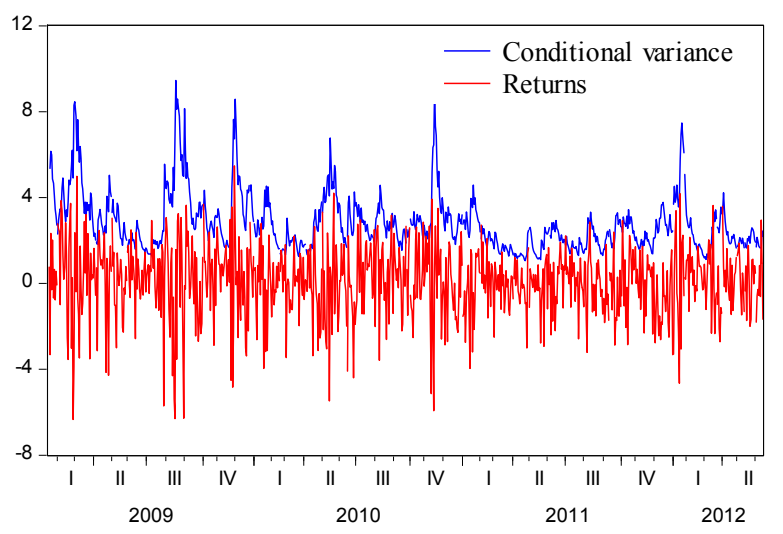

Financials

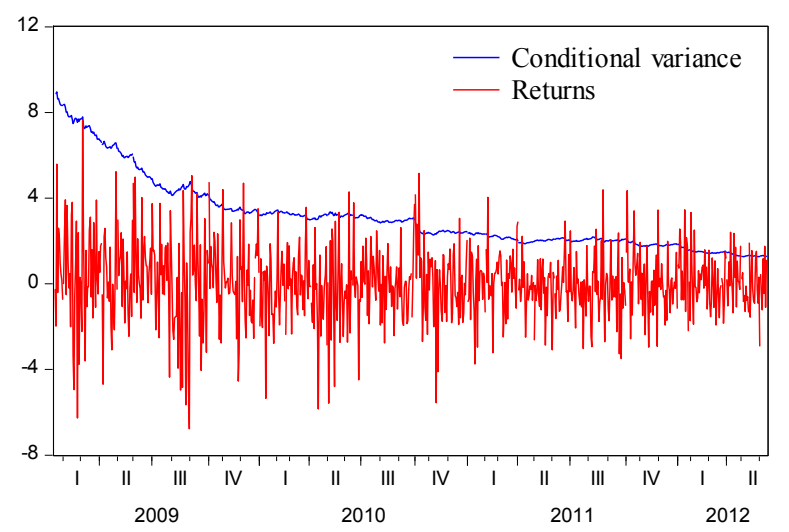

Industrials

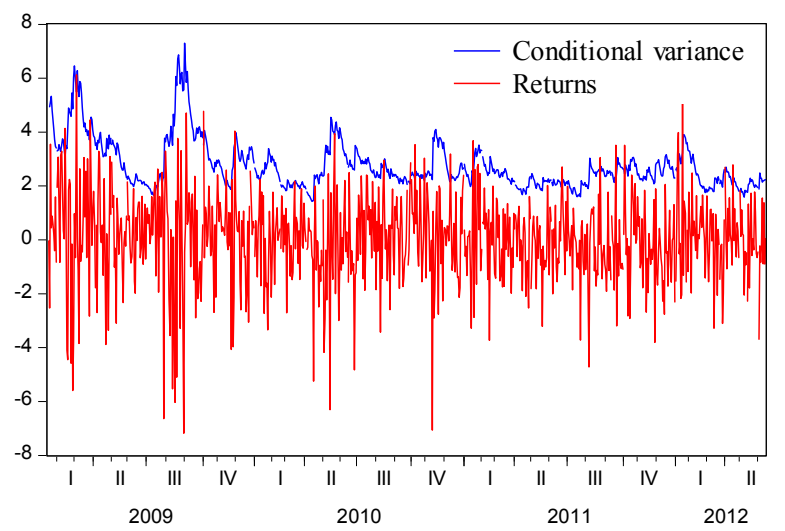


Information technology

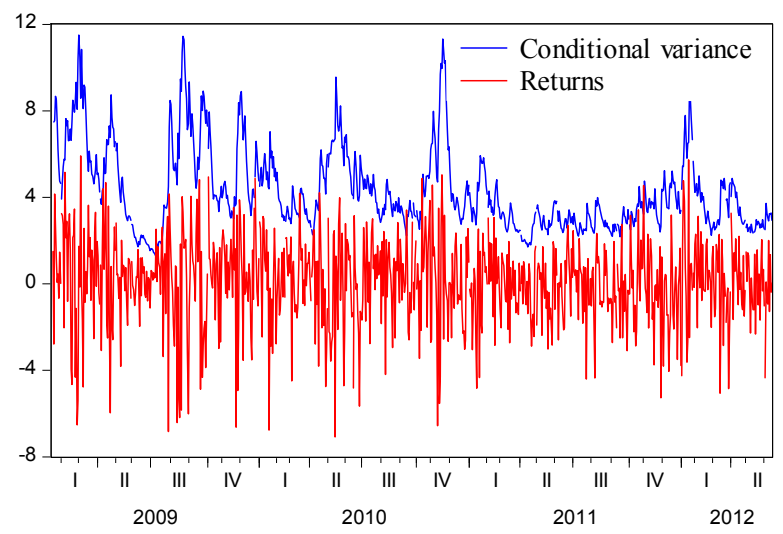

Telecommunications

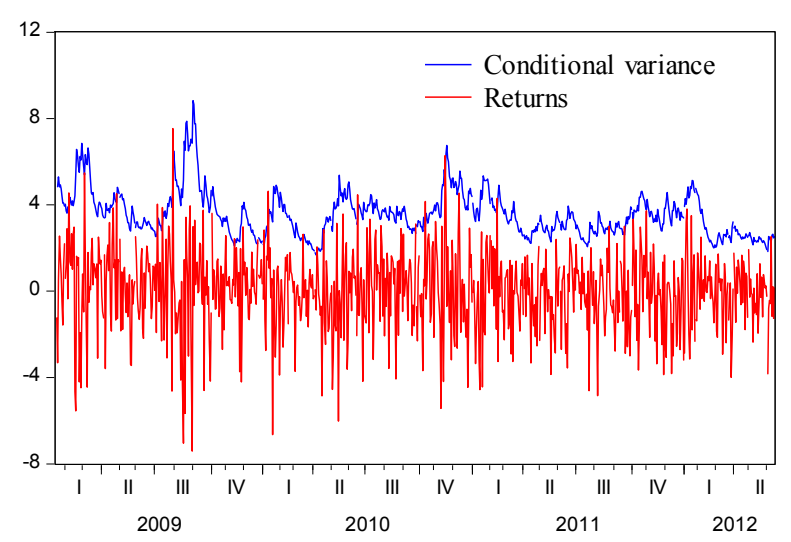

Materials

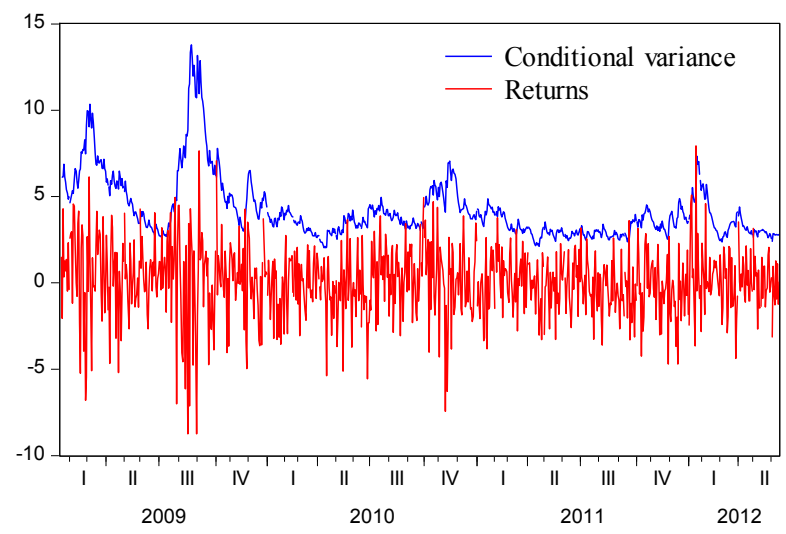

Utilities

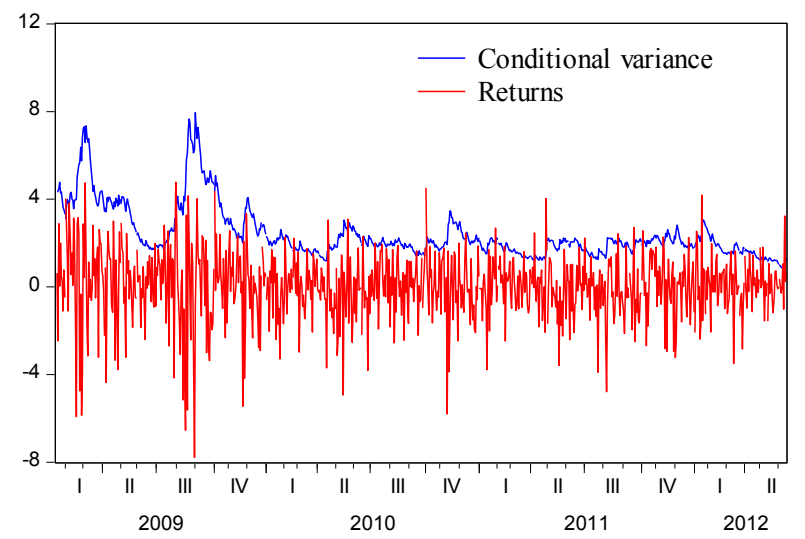

Shanghai Stock Exchange 180

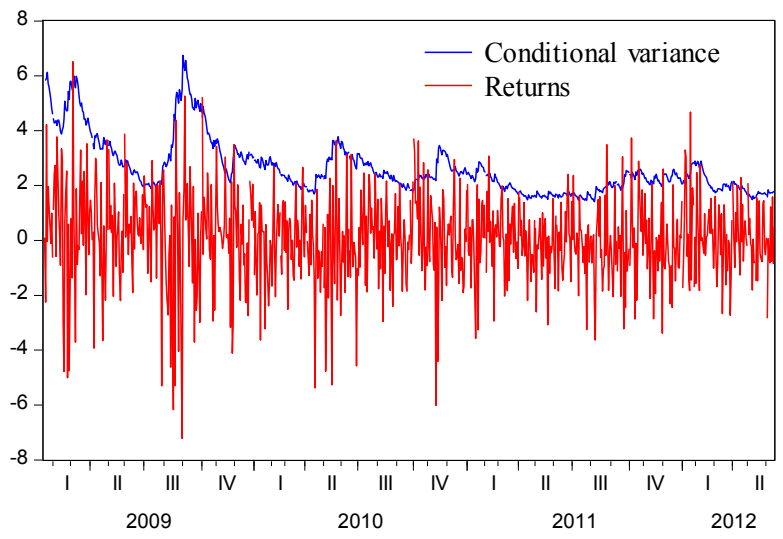

Figure 3. Conditional Volatility Estimates 